\title{
Social Responsibility and Ethics: A 20 Year Retrospective
}

\author{
Cecília Baranauskas \\ State University of Campinas \\ c.baranauskas@gmail.com
}

\author{
Clarisse S. de Souza \\ Pontifical Catholic University of \\ Rio de Janeiro \\ clarisse@inf.puc-rio.br
}

\author{
Kristina Höök \\ Royal Institute of Technology, \\ Sweden \\ khook@kth.se
}

\author{
Victoria Belloti \\ Lyft , US \\ bellotti@gmail.com
}

\author{
Virgílio Almeida \\ Federal University of Minas Gerais \\ virgilio@dcc.ufmg.br
}

\author{
Raquel O. Prates \\ Federal University of Minas Gerais \\ rprates@dcc.ufmg.br
}

\author{
Heloísa Candello \\ IBM Research - Brazil \\ heloisacandello@br.ibm.com
}

\begin{abstract}
It has been 20 years since we have organized the first edition of IHC in 1998. So much has changed regarding not only technology, but also how it is inserted in our society. During this time, technology and people's interaction with it have become ubiquitous and part of our everyday lives mediating many (if not most) of our ordinary activities from communicating with other people, to work, entertainment and Government services. As professionals who generate technology, this change has also raised our awareness, concern and attitude towards the social responsibility and ethics involved with developing technology and its use by society. In this panel, we discuss how social responsibility and ethics have changed and what is our role, as professionals, going forward.
\end{abstract}

\section{PARTICIPANTS}

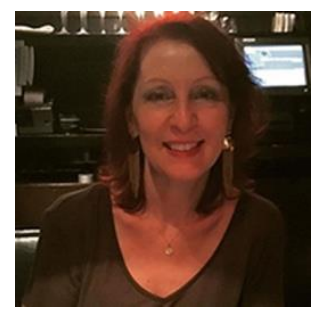

\section{Cecília Baranauskas}

Position: Computer technology has infiltrated our lives and cultures, transforming our ways of interacting, understanding, and living (in) the world. This presence has led to changes in our

Permission to make digital or hard copies of all or part of this work for personal or classroom use is granted without fee provided that copies are not made or distributed for profit or commercial advantage and that copies bear this notice and the full citation on the first page. Copyrights for components of this work owned by others than the author(s) must be honored. Abstracting with credit is permitted. To copy otherwise, or republish, to post on servers or to redistribute to lists, requires prior specific permission and/or a fee. Copyright 2018 SBC.

IHC 2018, Anais Estendidos do XVII Simpósio Brasileiro sobre Fatores Humanos em Sistemas Computacionais Outubro 22-26, 2018, Belém, Brasil TRILHA relationships with technology, with others, and with the process of building knowledge. Technology is a human creation; therefore, there is no neutrality in our relationship with it: we suffer the impact of technology and, at the same time, we are responsible for the form it takes and for the effects it causes. My contribution to the panel will seek to synthesize some achievements of the Brazilian IHC community on the theme of the panel (to give context) and bring to the discussion some conceptual aspects of the theme (on ethics, values and social responsibility). My position on the subject involves a subjectivist posture to understand the relation between people and technology, assuming and recognizing the need for social consciousness in design. Therefore, to discuss ethics and social responsibility in IHC, in my view, presupposes explicit philosophical bases (ontology, epistemology, axiology) from which we explain our methodological choices. I want to provoke a reflection on this awareness that I believe is necessary for those who work on the design (and engineering) of technology-based systems.

Short-bio: Cecília Baranauskas is a full Professor at the State University of Campinas (UNICAMP), Brazil; currently affiliated as collaborator at the Institute of Computing, where she developed her academic career. Co-founder and former coordinator of the Nucleus of Informatics Applied to Education, UNICAMP. Currently Member of the Board of Directors of the UNESCO Institute for Information Technology in Education (IITE) (2018-). Her formal education and academic collaboration include: BSc in Mathematics, Bachelor's and MSc in Computer Science and Doctorate in Electrical Engineering at UNICAMP, Brazil (1993); Honorary Research Fellow at Staffordshire University (2001) and Visiting Fellow at the University of Reading, UK, in the Laboratory of Applied Informatics with 
Semiotics (2002); Ibero-American Catedra UnicampSantander at Universidad Politecnica de Madrid, Spain (2006) studying accessibility issues in software engineering. Her research interests have focused on Human-Computer Interaction, Organizational Semiotics and Design of interactive computer-based systems in different domains (social, educational, work). She has led several projects with the support of funding agencies, having supervised more than 60 master's, doctoral and postdoctoral theses. She has received several awards for contribution throughout her career, such as: The Diploma of Educational Merit "Prof. Darcy Ribeiro" in 2006, from the City Hall of Campinas, The ACM SIGDOC Rigo Award in 2010, for contributions to the Design of Communication field, The First SBC-HCI Career Highlight Award in 2015, The UNICAMP Academic Recognition "Zeferino Vaz" in 2016. Research Productivity Fellow of the National Research Council $(\mathrm{CNPq}$ \#306272/2017-2). Full Curriculum Vitae: http://lattes.cnpq.br/1750385790843118

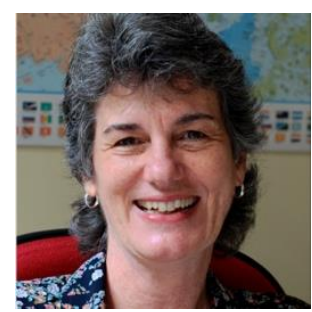

\section{Clarisse S. de Souza}

Position: Now that digital technology mediates almost all aspects of our personal, social, political and cultural lives, the time has come to help software designers and developers - and not only interaction designers understand how their work affects and changes the lives of individuals, groups, and society. Professional education in our country, and many others, has for a long time reinforced the idea that software engineers and other technical IT professionals (e.g. programmers, systems architects and analysts) do not have to deal with subjective issues like human values, users' expectations and capacities, computermediated social communication, ethical aspects of technology, and others. Subjectivity is typically thought of as "the HCI guys' domain". However, as recent EU data protection regulation [4] has eloquently shown, every segment of technology development contributes to 'reality construction' (with my nod of respect to Christiane Floyd [3]). One of the challenges that we have before us is to bring HCI knowledge and concerns into the software engineering territory, not only as a means to improve the quality of use and experience that end users have with increasingly sophisticated digital technologies, but much more importantly, I believe, as a means to help software designers and developers realize, understand and choose how their personal (and often unconscious) beliefs, values and intentions get encoded in software as digital speech acts. Speech act theory [5,6] has revolutionized language studies in the 1960's and 1970's by showing that the meaning of sentences and text includes the consequences and changes that the act of saying them can achieve. In the 1980's, the work of Terry Winograd and Fernando Flores [8] with the Language-Action Perspective (LAP), especially in the design of collaborative systems, warned us about the depth of social responsibility and action in which systems developers engage by writing 'digital texts' whose action by definition - affects the world where such systems are used. LAP was proposed as a 'perspective' based on Speech Act theory, with deep philosophical and ethical implications, but the evolution of HCI and Software Engineering research in the two or three decades that followed took another road.

My position in the panel, as an heir of LAP and early semiotic approaches to HCI and software development [7] where software is viewed as digital speech acts, i.e. pieces of human social communication expressed in artificial language, is that we need theories to account for the encoding and transmission of human intent, values and beliefs at the very core of software design and development. Semiotic Engineering [1,2], a semiotic theory developed in this community of Brazilian HCI researchers, is, in my view, a candidate for the job. However, more theories are needed to advance our knowledge and provide the necessary conditions for us to meet the legal and ethical imperatives of IT design and development.

Short-bio: Clarisse de Souza is a full professor of the Department of Informatics at the Pontifical Catholic University of Rio de Janeiro (PUC-Rio). She has a PhD in Computational Linguistics from PUC-Rio and is known for her work in Semiotic Engineering, a semiotic theory of Human-Computer Interaction. Because of her theoretical contribution to $\mathrm{HCI}$, Clarisse has received several awards in her career, including: the ACM SIGDOC Rigo Award in 2010, the CHI Academy Award in 2013, the IFIP/TC13 HCI Pioneers in 2014, one of the 54 Notable Women in Computing selected by the CRA-W/Anita Borg Institute in 2014, the Brazilian Computer Society (SBC) Scientific Merit Award in 2016, and the SBC/CEIHC Outstanding Career Award in HCI in 2017. She is the author or co-author of four books on Semiotic Engineering, published by The MIT Press (2005), Morgan \& Claypool (2009), and Springer International (2012 and 2016). Her 2016 book extends the reach of Semiotic Engineering research in order to account for meaning-related aspects of software design and development. In 2017 she took a sabbatical leave from PUCRio and spent one year as a senior researcher at IBM Research Brazil, investigating meaning encoding, interpretation and explanations for data-driven machine learning systems. Her research is currently funded by $\mathrm{CNPq}$, the Brazilian National Council for Scientific and Technological Development (Grant PQ1B \#304224/2017-0).

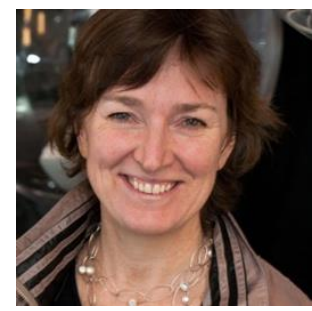

\section{Kristina Höök}

Position: In 2006, Susanne Bödker summarised some of the concerns we had at the time [10]. As technology had been traveling from the workplace into every walk of life, Bödker, had some serious concerns about where HCI was heading with this shift. Bödker was one of the strongest 
voices in shaping participatory design in the 70ies and 80ies, a highly political commitment to designing together with the workers who had to use the IT-tools provided for them. In the second wave of HCI, the same commitment was given to CSCW -- empowering collaborations between people. But in the third wave, a different commitment was called for. Many of us had started to care deeply about the whole range of human experiences, engaging in a different manner in the design process [14]. To properly engage with the design of games, social media, design touching our emotions, we had to work with the notion of felt life. There was a distinct shift to a process of experience design, borrowing methods from the industrial design and art scene, rather than focusing solely on the efficiency and empowerment of workers. Research through Design (RtD), that is bringing out many design concepts in order to properly understand the problem, was gaining popularity as the design process could no longer be seen solely as a rational, straightforward process of optimising the solution towards the tasks of the user.

While this shift was in many ways liberating, opening for a whole range of possible interactions, it also opened a can of worms when it came to ethical issues. Entering into the consumer marker also meant engaging with consumerism. Somewhat naively, HCI engaged with this third wave of technology without discussing the political changes that came with this shift. How could we give end-users any power to shape their lives when the tools provided were handed to them without giving them any power to influence their design? [12].

Even more difficult was - and still is - the issue of what happens when the third-wave tools and applications started to reach billions of users across the globe. Our field does not have the tools to work with the effects of scale [9]. Today we see the effects of fake news, social media, recommender systems, statistics on a large scale, in effect treating end users as masses providing their data, in turn enabling harvesting of value and selling more products.

My personal interest has been in what we can do as technology is creeping closer and closer onto our bodies [13]. While new smart materials and various AI-solutions offer amazing opportunities to shape aesthetically interesting expressions and experiences, engaging with application domains such as health, fashion, intimate care or domestic appliances, they also thrive on very personal data. The body becomes an open arena for politics. Gender, racism, norms and political power are enacted on and with the body. When the technologies close to our bodies scale to the masses -ethics will be even more deeply intervowen with design. As Elizabeth Grosz [1994] said, "Our bodies are completed by culture." That is, these interactions will change not only how we socialise or work, but how our bodies are constituted, how we move, to where, and with whom. How do we design our own bodies without loosing sight of our humaness? The way we engage with aesthetics in our design processes becomes the path to "knowledge, self-knowledge, right action, happiness, and justice." [15].

Short-bio: For many years, I lead a research centre named Mobile Life (2007-2017). The whole centre was committed to playfulness. Our credo was "Always engage! Always create! Always enjoy!". Our aim was to upgrade emotion, experience, playfulness from their position as the less valued pair in the rational-irrational, thinking-emotion, male-female dichotomies. During those years, I formed an agenda I named Soma Design based on the pragmatist philosophy and in particular the notion of somaesthetics. I now lead a research group at the Royal Institute of Technology (KTH) in Stockholm, Sweden, committed to designing with our bodies in an ethically defensible manner.

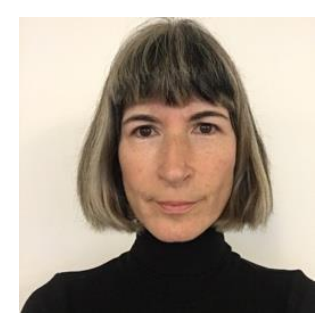

\section{Victoria Bellotti}

Position: Since I'm not an ethics expert, I'm going to use this panel as an opportunity to consider some long-term, perhaps 20-years into the future, ethical quandaries. My hope is that the other more expert panelists may be able to draw on lessons from the past 20 years that can help us deal with the next 20 years with some wisdom. I'm thinking of Lyft as great a case study for this panel as it was founded by two idealists who want to make one of the greatest sources of pollution on our planet, transportation, more sustainable over the coming years. They also maintain high standards of support for personal dignity for employees and users and go to great lengths to preserve user privacy. But, at every turn, there are ethical dilemmas to confront in growing this business and disrupting transportation. I'm not at liberty to disclose confidential information about Lyft's business, so I want to pose some hypotheticals here that may or may not be true of Lyft's business concerns, but certainly apply to the rideshare business in general:

Rideshare is making transportation more accessible to poorer communities that are ill served by public transportation. But what do we do about the fact that this may cause people to spread out and consume more transportation resources? The more generalized version of this quandary is, if you innovate to make something that consumes resources easier, then won't people just do more of it?

Over the past 10 years we have seen that people are not naturally inclined to share (goodbye sharing economy). And, whilst public transit and sharing your ride is best for the environment, it is not something most people aspire to do. How can we encourage people who can afford private transportation to reduce their personal transportation emissions by sharing more?

Every transportation innovation from horse-drawn carriages to autonomous vehicles has solved a problem, only to create more problems. In the US, fuel efficient cars just got bigger 
and bigger over the past 20 years. Shared bikes and scooters are a new, excellent way to reduce carbon emissions, but what do we do about the fact that it is less safe for people to use them than cars on busy city streets?

All major rideshare companies and car manufacturers are working on autonomous vehicles that will someday put drivers out of a job. About $3 \%$ of the US workforce is drivers (up to $5 \%$ in some areas). How do we transition ethically from driven to driverless? It's not just driving; automation is thought to threaten almost $50 \%$ of all jobs in the US.

Short-bio: I am a recently reformed research scientist (psychologist, ethnographer, UX researcher) now working in industry. Prior to arriving at Lyft in March of this year, I was especially interested in human motivations for different kinds of economic and lifestyle choices, especially transportation and health. Now I get to apply my expertise in helping to make Lyft's various services more attractive to and safe for users. I'm a proud member of the SIGCHI Academy in recognition of my scientific contributions, though I don't do academic research these days. Being at a start-up in hypergrowth is a very different way of life with little time for writing papers, though I am humbled and learning a lot from my incredible and enthusiastic new colleagues.

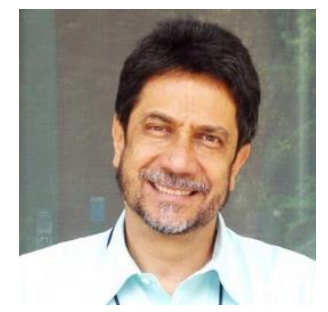

\section{Virgilio A. F. Almeida}

Position: My research interest is centered around the analysis and understanding of the impact of the digitalization of society, in the digital representation of people, images, things and objects and in the algorithms that manipulate these representations and make decisions. With the increasing digitalization of society and with the advancement of artificial intelligence and decision-making systems, new challenges and opportunities are put to the technical community. "Fake News", discrimination, violation of human rights are some examples of problems that became more visible with the rapid advancement of digital technologies. These are ethical and moral problems, that have social, economic and political impact. So, my contribution to the panel is twofold. First, I will show the type of empirical work we are doing to find out algorithm biases in the global platforms. Second, I will discuss governance mechanisms that can be created to minimize the risks and possible downsides of decisionmaking systems. I will introduce a conceptual framework for thinking about governance for AI, autonomous systems, and algorithmic decision-making processes.

Short-bio: Virgilio Almeida is a full professor of Computer Science at the Federal University of Minas Gerais (UFMG). He is also Faculty Associate at the Berkman Klein Center at Harvard University. Virgilio received his $\mathrm{PhD}$ degree in Computer Science at Vanderbilt University, a Master's degree in computer science at PUC-Rio and a bachelor degree in Electrical Engineering from UFMG. He held visiting positions in several universities and research labs, such as Harvard University (School of Engineering and Applied Sciences), New York University, Boston University, Santa Fe Institute and HP Labs.

Virgilio was the National Secretary for Information Technology Policies of the Brazilian government from 2011 to 2015. Virgilio is member of the Brazilian Academy of Sciences (ABC) and the Academy of Sciences for the Developing World (TWAS). A complete list of publications can be obtained at:

Google Scholar:

https://scholar.google.com/citations?hl=en\&user=Wbi6RfA AAAAJ\&view_op=list_works\&sortby=pubdate

DBLP:

https://dblp.uni-

trier.de/pers/hd/a/Almeida:Virg=iacute=lio_A=_F=

MODERATOR

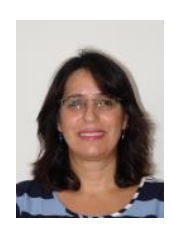

Raquel Prates is an Associate Professor at the Computer Science Department at the Federal University of Minas Gerais (UFMG). She has a $\mathrm{PhD}$ in Informatics from PUC-Rio and her main research interests lie in HCI and Collaborative Systems. She is active in the national and international HCI and CSCW communities, and is currently a member of the Brazilian Special Committee in HCI and the chair for Brazilian Special Committee in CSCW, associated to the Brazilian Computer Society (SBC). She has participated as program chair, program committee member and technical chair to many national and international events. Currently, she is the program co-chair for IHC 2018.

\section{REFERENCES}

1. Clarisse S. de Souza, Renato F. G. Cerqueira, Luiz M. Afonso, Rafael R. M. Brandão, Juliana S. J. Ferreira (2016) Software Developers as Users: Semiotic Investigations in Human Centered Development. Cham. Springer International.

2. Clarisse Sieckenius de Souza (2005) The semiotic engineering of human-computer interaction. Cambridge, Mass.: The MIT Press.

3. Floyd C. (1992) Software Development as Reality Construction. In: Floyd C., Züllighoven H., Budde R., Keil-Slawik R. (eds) Software Development and Reality Construction. Berlin, Heidelberg: Springer.

4. General Data Protection Regulation (EU) 2016/679 of the European Parliament and of the Council of the European Union. EUR-Lex. ELI: http://data.europa.eu/eli/reg/2016/679/oj

5. John L. Austin (1962) How to do things with words. Cambridge, New York. Harvard University Press. 
6. John R. Searle (1969) Speech acts: An essay in the philosophy of language. Cambridge, New York. Cambridge University Press.

7. Peter B $\emptyset$ gh Andersen (1990) A theory of computer semiotics : semiotic approaches to construction and assessment of computer systems. Cambridge, New York: Cambridge University Press.

8. Terry Winograd and Fernando Flores (1986) Understanding computers and cognition : a new foundation for design. Norwood, NJ: Ablex.

9. Brown, B., Bødker, S., \& Höök, K. (2017). Does HCI scale?: scale hacking and the relevance of HCI. interactions, 24(5), 28-33.

10. Bødker, S. (2006, October). When second wave HCI meets third wave challenges. In Proceedings of the 4th Nordic conference on Human-computer interaction: changing roles(pp. 1-8). ACM.

11. Grosz, Elizabeth. 1994. Volatile Bodies: Toward a Corporeal Feminism. Bloomington: Indiana University Press.

12. Höök, K. (2006, October). Designing familiar open surfaces. In Proceedings of the 4th Nordic conference on Human-computer interaction: changing roles (pp. 242-251). ACM.

13. Höök, K. (2018). Designing with the Body: Somaesthetic Interaction Design. MIT Press.

14. Höök, K., Sengers, P., \& Andersson, G. (2003, April). Sense and sensibility: evaluation and interactive art. In Proceedings of the SIGCHI conference on Human factors in computing systems (pp. 241-248). ACM.

15. Shusterman, Richard. (2003). Somaesthetics and The Second Sex: A Pragmatist Reading of a Feminist Classic. Hypatia 18 (4): 106-136. 